\title{
Introdução
}

\section{As dobras entre o dentro e o fora}

Fábio Mallart*

http://orcid.org/0000-0001-9033-030X

Manuela Ivone Cunha**

http://orid.org/0000-0001-9608-164X

Lá se vão mais de dois anos quando este Dossiê começou a ser imaginado. O tema e os contornos que lhe dão forma remetem à realização de um seminário, em novembro de 2017, nas dependências do Instituto de Ciências Sociais da Universidade do Minho, em Braga, Portugal. No centro de tais discussões estava a prisão, mais especificamente, os fluxos, as conexões e as ressonâncias que tensionam a imagem do cárcere como espaço autocentrado, como unidade de análise, como categoria que parece trazer consigo mesma uma espécie de delimitação invariável. Sem perder de vista as dinâmicas intramuros, ao longo do referido evento, que reuniu investigadores portugueses, brasileiros e espanhóis, tratou-se de prospectar as extensões do cárcere: a prisão que se conecta às diversas formas de controle a céu aberto; que opera em conjunto com uma multiplicidade de equipamentos de assistência social e de saúde; que funciona em correlação com controles de fronteira; que produz a mobilização de familiares e de outros agentes sociais ao redor de seus muros.

$\mathrm{Se}$, em parte, o conjunto dos artigos que ora apresentamos é o prolongamento de tais discussões, vale ressaltar que este Dossiê também pode ser lido como um prolongamento de outra ordem, mais propriamente, em relação a um vasto campo de estudos, no qual a prisão emerge como objeto de diferentes pesquisas - com distintos enfoques, questões e pressupostos. Prolongamento este que não se contenta apenas em estender os traçados por outros esboçados, mas que visa produzir mudanças 
de direções e quebras. Se, por um lado, trata-se de esticar linhas de pensamento já fixadas, por outro, busca-se deslocá-las.

Sabe-se que durante o século $\mathrm{xx}$ diversos pesquisadores têm se debruçado sobre as instituições prisionais, objeto que pouco a pouco se consolidou no campo das ciências sociais. Evidentemente, no âmbito destas poucas linhas, não se almeja fornecer ao leitor um apanhado exaustivo desses estudos. Antes, trata-se de perscrutar um recorte singular, a saber, a maneira como as relaçóes entre o mundo intramuros e o mundo extramuros vem sendo pensada e, mais do que isso, os níveis em que essas relações se estabelecem.

Vale recordar que alguns dos estudos que pautaram muitas das análises acerca das prisões e que desenvolveram uma sólida agenda de questões e problemas de pesquisa, tendo sido publicados sobretudo a partir de 1940, nos Estados Unidos, centraram as suas reflexões no lado de dentro dos muros prisionais. Do clássico estudo de Clemmer (1940) e sua noção de "prisionização", que designa o processo de socialização e aculturação dos internos em valores carcerários, passando pelo trabalho de Sykes e Messinger (1960), que ratificam essa análise, argumentando que a cultura prisional e o sistema social que ela regula figuram como mecanismo endógeno, isto é, como efeito das privações impostas pela detenção, até os escritos de Goffman (1974, p. 11) e o conceito de "instituição total", em que um grande número de indivíduos, separados da sociedade por considerável período de tempo, "levam uma vida fechada e formalmente administrada". Esses trabalhos, de um modo ou de outro, com maior ou menor ênfase, acabam por reforçar a imagem da prisão como uma espécie de realidade "no vácuo", apartada dos contextos que a englobam e das forças que para além dos muros participam de sua configuração (Cunha, 2004, p. 152).

Ora, é exatamente o pressuposto de que o cárcere figura como um mundo social à parte que durante anos parece ter servido de base ao campo dos estudos prisionais, como se a reclusão fosse, de fato, um hiato social e cultural, um intervalo posto entre parênteses. Ainda assim, é inegável a constatação de que outros trabalhos, coetâneos desse período, já manifestavam alguns traços das possíveis relações entre o dentro e o fora, entre prisão e sociedade, a começar pelo estudo de Rusche e Kirschheimer (2004), que fora publicado originalmente em 1939, e no qual a prisão participa na regulação do mercado de trabalho, abrindo e fechando as suas comportas de acordo com as variações dos ciclos econômicos.

Em 1975, Michel Foucault, com a publicação de "Vigiar e punir" (1987), lançaria novas bases para a compreensão do aparato prisional. Em tal obra, o cárcere não emerge como mundo à parte, mas, pelo contrário, como um instrumento de controle social e "um revelador da sociedade" (Cunha, 2015, p. 186), afinal, as ponderações de Foucault dizem menos respeito à prisão do que ao desenvolvimento e espraiamento de novas 
tecnologias de poder, que conformariam uma sociedade disciplinar. Lembremo-nos, por exemplo, de seus apontamentos acerca do "arquipélago carcerário" (1987, pp. 243-254), em que, por meio das interligações disciplinares, a prisão é só uma peça, estando conectada a uma série de outros mecanismos - escolas, conventos, hospitais, orfanatos etc -, que exercem um poder de normalização. Com efeito, para o autor a prisão está distante de ser um mero espaço de confinamento, afinal, a força das muralhas não reside na sua impermeabilidade material, mas nos canais que as atravessam, na capilaridade que as abastece e as esvazia. Longe de ser a altiva fortaleza, a prisão é “a casa-coador, a casa de passe, o inevitável motel” (Foucault, 2015, p. 143).

Em outro registro, Virilio (1996), ao refletir sobre as articulações entre velocidade e política, tecendo considerações acerca das ruas, cidades e aparatos arquitetônicos como a fortaleza, também notara que as praias pantanosas que rodeavam as cidades fortificadas, assim como prisões, hospícios e casernas, "resolvem mais um problema de circulação que de enclausuramento ou de exclusão" (Virilio, 1996, p. 23). Na condição de barreiras, de filtros que regulam as massas proletarizadas, esses lugares possibilitam o controle da circulação e a administração da velocidade - de pessoas, mercadorias e bens.

Nessa chave, a insistência em tomar a reclusão como intervalo e interrupção, como unidade de observação e análise autocentrada - "verdadeira noção-paradigma dos estudos prisionais" (Cunha, 2004, p. 153) -, além de representar sistemas de pensamento que têm como base o pressuposto de que os muros separam os presos de suas relações anteriores e exteriores, ao postular a ruptura, acaba por reforçar histórica e politicamente a diferença entre um "nós” e os "outros", manifestando e assentando, em um só golpe, "as bases para o exercício do poder" (Godoi, 2017, p. 38). Ademais, tal enfoque acaba por desconsiderar as mutações que caracterizam os sistemas punitivos contemporâneos, desde os processos de abertura da instituição seja através da regulação externa ou por meio dos fluxos de bens e de serviços de toda a ordem -, passando pela explosão dos mecanismos de controle a céu aberto, até as reconfigurações no próprio exercício do poder de punir, que conduzem ao movimento de destotalitarização da instituição (Chantraine, 2006).

Não é em vão que ao longo dos últimos anos, embora haja trabalhos que enfoquem o perímetro institucional - o problema não está em analisar as dinâmicas intramuros, mas em fazer dessa separação entre o dentro e o fora um ponto de partida irrefletido -, multiplicaram-se os estudos que visam deslindar as dobras e as interfaces entre os dois lados das muralhas, e isso de diferentes ângulos. Somente para citar alguns exemplos, ao abordar as relações conflituosas que se tecem entre a prisão e o seu entorno imediato, pode-se analisar como os efeitos estigmatizantes do cárcere se propagam para além do perímetro interno, projetando-se na vizinhança imediata (Combessie, 2002 e 2009). 
Em outra chave, há todo um corpo de trabalhos que centram as suas reflexões nos efeitos que as grades geram para familiares e parceiros de presos e presas, justamente porque as suas vidas são afetadas pela reclusão - seja porque estes têm de se adaptar às normas que regem o funcionamento da instituição carcerária, seja porque, mesmo não estando detidos(as), as suas vidas também passam a ser reguladas indiretamente pelo cárcere (Touraut, 2009; Comfort, 2007).

Ainda na esfera das possíveis continuidades entre o dentro e o fora, a explosão da população carcerária durante as últimas décadas, o que David Garland (2008) chamou de encarceramento em massa e Loïc Wacquant, em uma designação mais certeira, de encarceramento concentrado, fez surgir uma série de estudos que enfocam o imbricamento entre prisões e zonas periféricas das cidades, elo que coloca uma série de questões sobre as fronteiras do cárcere. Por certo, a lista de trabalhos que seguem nessa direção é ampla, cabendo aqui apenas apontar o fio transversal que os aproxima. Tais estudos evidenciam o fato de que as prisões se encontram ligadas a determinados territórios urbanos, tais como periferias e favelas brasileiras (Barbosa, 2005), guetos estadunidenses (Wacquant, 2007), townships sul-africanas (Waltorp e Jensen, 2019), banlieues parisienses (Bony, 2015), ou mesmo bairros portugueses (Cunha, 2002) e camaroneses (Morelle, 2015) habitados pelas populações mais pobres, o que acaba por constituir um circuito prisão-periferia. Entre as potencialidades desses escritos, sublinha-se a ênfase na concentração espacial do encarceramento, a incorporação desses bairros pela prisão - assim como da prisão pelos bairros -, a disseminação da experiência prisional entre determinados territórios urbanos e a translocalidade das tramas sociais da prisão.

É justamente na extensão dessas “dobras entre o dentro e o fora dos muros" (Vera Telles, na Apresentação) que este Dossiê se situa, estendendo e deslocando linhas de pensamento que o precedem. No artigo de abertura, Manuela Ivone Cunha, ao comparar materiais etnográficos produzidos numa mesma prisão, antes e depois do processo de encarceramento massivo que a enlaçou a um conjunto de bairros urbanos, centra as suas reflexões no modo como a reorganização das fronteiras intraprisonais, provocada pela interconexão entre o intra e o extramuros, rebate nas experiências corpóreas e sensoriais das internas. Focada nas relações entre socialidade e corporalidade, a autora nos mostra como a reconfiguração da socialidade "enquadrou a transformação de uma incorporação na e da prisão". Na medida em que o dentro e o fora tornam-se contíguos, social e moralmente, antigas fronteiras internas se esbatem, fazendo surgir uma comunidade de sentidos, emoções e agencialidade.

Gilles Chantraine e Laura Delcourt, baseando-se em pesquisa qualitativa sobre as condições de soltura dos presos mais pobres da França - e a busca por moradia enfocam as continuidades experienciais dos dois lados das muralhas, recolocando a 
passagem pelo encarceramento em uma experiência de carceralidade que a engloba e desloca. Ao sugerir uma abordagem da prisão em termos de "desespecificação", o que não significa negar as singularidades da instituição, mas objetivar a participação do cárcere em novas formas de dominação que o ultrapassam, ao mesmo tempo que tendem em direção a ele, os autores deixam de centrar as suas reflexões nas ligações que conectam prisão e bairros populares, ajustando o foco aos processos que marcam a saída da instituição. No esforço de perseguir a "desespecificação" analítica da prisão, evidencia-se, contra o reducionismo que consiste em ver na libertação o término da punição, que a saída do cárcere não coloca fim à pena, mas, pelo contrário, é parte integrante dela. Ademais, tendo-se em vista as dinâmicas dos serviços de moradia - marcados pela insalubridade, violência e disciplina -, constata-se que esses equipamentos prolongam a experiência carcerária.

Se em tal artigo a experiência de carceralidade não termina com a saída da prisão, mas se estende a outras instituições, notadamente aos aparatos de moradia, nas reflexões propostas por Fábio Mallart o cárcere emerge como um só ponto de um vasto circuito ou, para mobilizar os termos do autor, como uma ilha - aberta, porosa e ressoante - de um arquipélago. Ao retomar as reflexões de Aleksandr Soljenítsin (2017) e Michel Foucault (1987) sobre a noção de arquipélago, o autor, com base em pesquisas etnográficas realizadas ao longo dos últimos quinze anos, anota conexões e ressonâncias que aproximam as prisões de uma miríade de aparatos punitivos, bem como de outros tantos equipamentos de saúde e de assistência social, além de determinadas zonas urbanas como a chamada cracolândia. Porém, já não se trata, como nas reflexões foucaultianas sobre o "arquipélago carcerário", de ajustar multiplicidades aos aparelhos de produção, mas de gerir a dispersão, colocando amplos contingentes populacionais para circular, sem deixar de confinar. Ao demonstrar que o desafio posto às instituições que conformam o arquipélago nos tempos que correm consiste em gerir populações e territórios negros, pobres e periféricos, sugere-se algumas pistas que possibilitam vislumbrar as engrenagens que, historicamente, fizeram com que o arquipélago ganhasse corpo, tanto em sua face punitiva quanto assistencial.

Tendo como base a análise de documentos, bem como a realização de entrevistas e pesquisa de campo junto a homens e mulheres submetidos a sistemas de monitoramento eletrônico, Ricardo Campello analisa a política de monitoração no Brasil, esmiuçando os impactos sobre a vida de indivíduos rastreados nos estados de São Paulo e Rio de Janeiro. Linha após linha, o autor nos mostra a sobreposição entre práticas de monitoramento e de encarceramento. Ao contrário de fomentar o desencarceramento, tal como fora anunciado quando da formulação da política, nota-se que a supervisão eletrônica é aplicada de modo complementar ao cárcere, estendendo o controle penal. Interessado nas interfaces entre a prisão, o monitora- 
mento eletrônico e os processos de subjetivação desencadeados por tal acoplamento, o autor, valendo-se de reflexões sobre as transformações operadas pelo poder de punir, mostra que a prisão, virtualizada através do uso das tornozeleiras eletrônicas, se desterritorializa, atualizando-se nos lugares por onde circula o indivíduo monitorado - no seu trabalho, na sua casa e no seu bairro. Desse prisma, o dentro e o fora atingem um tal grau de indiferenciação que os muros não circunscrevem o espaço penal, fazendo emergir a figura do preso como carcereiro de si mesmo.

Esticando toda uma linha de trabalhos que abordam os efeitos do encarceramento para familiares e parceiros(as) de presos(as), no artigo de Caroline Touraut a influência da prisão para além dos muros se dá por meio da "experiência carcerária ampliada”, que induz a uma série de conflitos com a instituição prisional. Em certa medida, trata-se de uma situação social singular, em que os parentes daqueles que se encontram atrás das grades têm de lidar com os numerosos danos econômicos e sociais do encarceramento. Tomando como fio condutor de suas análises os escritos redigidos por tais atores, que permitem apreender suas queixas em relação às prisões, bem como as suas experiências, a autora lança luz sobre as principais dificuldades enfrentadas, desde as menções às condições materiais do cárcere, passando pelo sentimento de desprezo e invisibilidade experimentados, até os questionamentos no que concerne ao significado das inúmeras regras carcerárias. Nesse cenário, a invocação de um quadro jurídico, uma humanidade comum e seus sofrimentos funcionam como argumentos para reivindicar reconhecimento e direitos.

Em outro registro, Antônio Rafael Barbosa reflete sobre dois conceitos que circulam pelas cadeias brasileiras, "comportamento" e "proceder". Próximos em termos semânticos, ambos "projetam linhas de afirmação dos valores", possibilitando não só análises acerca dos nexos que articulam moral e política, mas também reflexões sobre a existência de um fundo valorativo comum que conecta as cadeias e as ruas. No centro de suas análises está a obra "Quatrocentos contra Um: uma história do Comando Vermelho”, produzida por William da Silva Lima, na qual o autor, preso durante a ditadura militar como ladrão de bancos, tece potentes reflexões sobre a experiência prisional. Para Barbosa, que coloca as teorias sociais dos presos no mesmo patamar das teorias sociológicas ou antropológicas, o continuum carcerário que liga as favelas e as quebradas às prisões passa por esse fundo valorativo que se alastra pelo tecido social e urbano, seja por meio dos corpos que vão e vêm, das letras dos rappers, das relações afetivas ou mesmo das guerras travadas contra o "sistema", misturando-se a outras tantas crenças e valores.

Ao pensarmos nos inúmeros fluxos que cortam os muros - como já dissera Antônio Rafael Barbosa, "a cadeia se constitui na medida do seu atravessamento, daquilo que põe em movimento" (2005, p. 317) -, a imagem que ganha força é a dos 
mil canais que correm por todos os lados, por cima e por baixo. Nesse ponto, Rafael Godoi, com base em análises sobre os relatórios produzidos pela Defensoria Pública do Rio de Janeiro no âmbito de um programa de monitoramento do sistema prisional, sugere que a erosão das fronteiras também pode se dar sobre um eixo vertical. Em seus termos, "mais escalando estruturas de poder, do que difundindo efeitos sobre o tecido social". Desse ângulo, a porosidade se manifesta a partir do deslocamento dos centros de poder para fora e para cima, ou seja, para os estratos mais altos da burocracia administrativa que, em parte, retiram das mãos daqueles que dirigem a prisão um tanto do poder discricionário. Ao explorar os relatos de práticas, enunciados e interações que evocam a lei, o direito e a autoridade no interior de unidades precárias e superlotadas, o que o autor demonstra é a existência de um campo de lutas que transborda o perímetro institucional - e essa é a provocação - para cima.

Seja do ponto de vista das práticas, políticas, códigos, enunciados e valores que vazam pelos muros, difundindo-se pelo tecido social e urbano - poder-se-ia dizer que este é o ângulo das lateralidades -, seja do prisma da escalada para fora e para cima dos limites prisionais (as verticalidades), ou mesmo da análise que realça a existência de subterrâneos dentro das prisões, demonstrando que o cárcere não figura como bloco monolítico, mas como um espaço matizado e fragmentado, poroso internamente - aqui, ganham relevo as profundidades (Mallart, 2019) -, o fato é que a prisão é muito mais esponjosa do que propriamente rija. Longe das representações que traçam alguns riscos limitando o dentro e o fora, em seguida, dividindo o interior em quadrados, retângulos ou círculos, a imagem que este Dossiê projeta é a dos inúmeros fios, canais e dutos que, emaranhados, correm em todas as direções. Que o leitor ou a leitora sinta-se à vontade para puxar uma dessas linhas, que as prolongue ou torça. E que, ao fazê-las mudar de direção, desenhe outras. 


\section{Referências Bibliográficas}

Barbosa, Antônio Rafael. (2005), Prender e dar fuga: biopolitica, tráfico de drogas e sistema penitenciário no Rio de Janeiro. Rio de Janeiro, tese de doutorado, Museu Nacional, Universidade Federal do Rio de Janeiro.

Bony, Lucie. (2015), "La prison, une cité avec des barreaux? Continuum socio-spatial par-delà les murs". Annales de Géographie, 702-703: 275-299.

Chantraine, Gilles. (2006), “La prison post-disciplinaire”. Déviance et Société, 3 (30): 273-288.

Clemmer, Donald. (1940), The prison community. Nova York, Rinehart \& Co.

Combessie, Philippe. (2002), "La ville et la prison une troublante cohabitation". Revue Projet, 269: 70-76.

Combessie, Philippe. (2009), "Flux migratoires, villes, prisons: analyse sociologique d'une forme de canalisation des circulations humaines". In: Herzog-Evans, M. (org.). La prison dans la ville. Toulouse, Eres, pp. 15-44.

Comfort, Megan. (2007), "Partilhamos tudo o que podemos: a dualização do corpo recluso nos romances através das grades”. Análise Social, 185 (XLII): 1055-1079.

Cunha, Manuela I. (2002), Entre o bairro e a prisão: tráfico e trajectos. Lisboa, Fim de Século.

Cunha, Manuela I. (2004), "As organizações enquanto unidades de observação e de análise: o caso da prisão”. Etnográfica, 8 (1): 151-157.

Cunha, Manuela I. (2015), “Da relação prisão-sociedade: atualização de um balanço”. In: Cunha, Manuela I. (org.). Do crime e do castigo: temas e debates contemporâneos. Lisboa, Mundos Sociais, vol. 1, pp. 181-200.

Foucault, Michel. (1987), Vigiar e punir: nascimento da prisão. Petrópolis, Vozes.

Foucault, Michel. (2015), Ditos e escritos. Vol. Iv: Estratégia, poder-saber. Rio de Janeiro, Forense Universitária.

GARLAND, David. (2008), A cultura do controle: crime e ordem social na sociedade contemporânea. Rio de Janeiro, Revan.

Godor, Rafael. (2017), Fluxos em cadeia: as prisões em São Paulo na virada dos tempos. São Paulo, Boitempo.

Goffman, Erving. (1974), Manicômios, prisões e conventos. São Paulo, Perspectiva.

Mallart, Fábio. (2019), Findas linhas: circulações e confinamentos pelos subterrâneos de São Paulo. São Paulo, tese de doutorado, Faculdade de Filosofia, Letras e Ciências Humanas, Universidade de São Paulo.

Morelle, Marie. (2015), "La prison, la police et le quartier: gouvernement urbain et illégalismes populaires à Yaoundé”. Annales de Géographie, 702-703: pp. 300-322.

Rusche, Georg \& Kirchheimer, Otto. (2004), Punição e estrutura social. Rio de Janeiro, Revan.

Soljenítsin, Aleksandr. (2017), O Arquipélago Gulag. Porto, Sextante. 
Sykes, Gresham \& Messinger, Sheldom. (1960), “The inmate social system”. In: Cloward,

R. et al. Theoretical studies in social organization of the prison. Nova York, Social Research Council, pp. 5-19.

Touraut, Caroline. (2009), "Entre détenu figé et proches en movement: l'expérience carcérale élargie: une épreuve de mobilité”. Recherches Familiales, 6: 81-88.

Virilio, Paul. (1996), Velocidade e política. São Paulo, Estação Liberdade.

WACQuANT, Lö̈c. (2007), Punir os pobres: a nova gestão da miséria nos Estados Unidos. Rio de Janeiro, Revan.

Waltorp, Karen \& Jensen, Steffen. (2019), “Awkward entanglements: kinship, morality and survival in Cape Town's Prison - township Circuit". Ethnos, 84 (1): 41-55.

Texto recebido em 7/10/2019 e aprovado em 11/10/2019.

DOI: $10.11606 / 0103-2070 . t s .2019 .162973$

FÁBIO MALLART é mestre em antropologia social e doutor em sociologia pela Universidade de São Paulo (USP).E-mail: mallart82@yahoo.com.br.

MANUELA IVONE CUNHA é doutora em antropologia, agregação em sociologia e professora da Universidade do Minho. É membro do Centro em Rede de Investigação em Antropologia, Universidade do Minho (CRIA - UMinho).E-mail: micunha@ics.uminho.pt. 